\title{
Meta 19 do Plano NaCiONAL De EduCAÇÃO: GESTÃO DEMOCRÁTICA OU GESTÃO GERENCIALISTA
}

\author{
Rudnei Joaquim Martins ${ }^{1}$ \\ Valéria Silva Ferreira ${ }^{2}$
}

Resumo: faz-se uma revisão sobre a democratização da gestão da educação básica pública, ao discutir a Meta 19 do PNE 2014-2024, princípio constitucional orientador do Sistema Nacional de Educação.Busca-se interpretar o conteúdo da Meta com base na CF/1988, na LDB/1996, no PNE 2001-2010 e na CONAE/2010. Propõe-se uma reflexão sobre as produções bibliográficas acerca da temática. Conclui-se que a Meta 19 e suas Estratégias são tecnologias utilizadas pelo Estado para implantar políticas neoliberais, utilizando-se de discurso democrático para implementar políticas de gestão gerencialista.Por ser um conceito polissêmico e multidimensional, a gestão democrática aparece de forma genérica no documento, propiciando entendimentos gerencialistas.

Palavras-chaves: Políticas Educacionais; PNE2014-2024; Meta 19;Gestão Democrática.

\section{Goal 19 of National Education Plan: democratic administration our management administration policies}

Abstract: A review of the democratization of public basic education administration is made by discussing Goal 19 of PNE 2014-2024, the constitutional principle guiding the National Education System. We seek to interpret the content of the Goal based on CF/1988, LDB/1996, PNE 20012010 and CONAE/2010. A reflection on the bibliographical productions on the subject is proposed. It is concluded that Goal 19 and its Strategies are technologies used by the State to implement neoliberal policies, using democratic discourse to implement management administration policies. Because it is a polysemic and multidimensional concept, democratic administration generally in the document, providing managerialist understandings.

Keywords: Educational Policies; National Education Plan (2014-2024); Goal 19; Democratic administration.

\section{INTRODUÇÃO}

Este artigo pretende discutir a Meta19 do Plano Nacional de Educação (PNE 2014-2024), questionando se estamos diante da conquista da gestão democrática da educação ou se a Meta está contribuindo para a implantação de uma gestão gerencialista. O PNE 2014-2024 determina as Metas e Estratégias para a política educacional no período de dez anos e abrange as grandes áreas da educação; possui um eixo organizador estruturado a partir de 20 Metas com

\footnotetext{
${ }^{1}$ Universidade do Vale do Itajaí. (martinsrudnei@gmail.com)

${ }^{2}$ Universidade do Vale do Itajaí. v.ferreira@univali.br
} 
suas respectivas Estratégias, servindo de base para todo o Sistema Nacional de Educação (SNE).

A Meta 19 tem o objetivo de aprimorar a gestão democrática da educação pública propondo formas de participação e contribuindo com os processos de autonomia pedagógica, administrativa e de gestão financeira das escolas públicas, paralelo a processos de prestação de contas junto às comunidades escolar e local para o controle social da educação (BRASIL, 2014b). Para tanto, a Meta apresenta Estratégias que garantam a participação coletiva de todos os segmentos que compõem a comunidade escolar. Desta forma, buscamos refletir se os enunciados contidos na Meta 19 atendem aos princípios democráticos que foram assegurados tanto na Constituição Federal de 1988 (CF/1988), como também na Lei de Diretrizes e Bases da Educação Nacional de 1996 (LDB/1996).

Por outro lado, a gestão democrática aparece apenas como uma tecnologia governamental que está para controlar e fiscalizar a escola, em um novo modelo de gestão do setor público denominado de gerencialismo. O gerencialismo, segundo Ball $(2005,2006)$, se mostra como uma nova forma de poder inserida no setor público, um poder que deriva da cultura empresarial,que busca a competitividade para alcançar performatividade, produtividade e desempenho.

Desse modo, a Meta 19 reserva ao Estado o papel de regulador e avaliador, na busca de garantir a governamentalidade ${ }^{3}$, ainda que se utilize de um discurso democrático. Dito isso, não somos contra as tecnologias utilizadas pelo Estado para estabelecer a gestão democrática na educação básica pública no que diz respeito as regras e procedimentos, pois "o poder possui uma eficácia produtiva, uma riqueza estratégica, uma positividade” (MACHADO, 2016, p. 20). Porém, quando o Estado utiliza destas tecnologias somente para aumentar a utilidade econômica e diminuir a força política da população, pode comprometer o estado democrático de direito estabelecido no Artigo $1^{\circ}$ da CF/1988, transformando a democracia somente para disciplinarem e docilizar.

Para Lessard (2016), as políticas podem ser analisadas como tecnologias que geram textos, que transmitem afirmações a respeito do mundo; produzem

${ }^{3}$ Para Foucault (2016), a governamentalidade está na arte de governar, pois existe uma triangulação de formas de gerir a sociedade, por meio de dispositivos e de mecanismos, tais como: soberania, disciplina e gestão, isso ocorre pois a governamentalidade vincula-se ao exercício de gestão das coisas e das pessoas pelo Estado. 
estruturas de realidades e de significado com as quais e dentro das quais, determinada política é pensada e dita. Elas incorporam vontades, pretensões, direitos ou reivindicações de falar com autoridade sobre uma área e sobre práticas sociais, legitimam e iniciam práticas novas ou restauram outras antigas, além de privilegiarem certas visões e interesses específicos.

Segundo essa perspectiva, as políticas, são ao mesmo tempo, sistemas simbólicos e dispositivos práticos, dotadas de uma força semântica e ontológica, contribuindo para construir um universo de significados feito de relações, causas e efeitos, além de fenômenos inevitáveis ou aos quais é preciso adaptarse imperativamente. Isso porque, a linguagem das políticas edifica uma visão do mundo, define ou redesenha as fronteiras e cria um espaço para agir, excluindo possibilidades e legitimando novas vozes, pois está vinculada a acontecimentos e os transforma em narrativas (LESSARD, 2016).

\section{CONTEXTUALIZANDO A GESTÃO DEMOCRÁTICA A PARTIR DA CF/1988}

As políticas para a educação que surgem no período da redemocratização do Brasil sofrem influência da política neoliberal, mesmo com a resistência de alguns setores da sociedade organizada e dos movimentos sociais. Neste processo, organizações como o Fórum Nacional em Defesa da Escola Pública, sindicatos de trabalhadores da educação, entidades acadêmico-científicas, entidades estudantis, movimentos populares, entre outros, passaram a unir forças contra a nova ordem mundial (BOLLMANN, 2010). Segundo a autora, a gestão democrática dos sistemas de ensino se legitima no Brasil primeiramente a partir da promulgação da CF/1988, que apresenta de forma clara, no Artigo 206, quais os princípios a serem adotados no ensino público eentre eles destacase "VI - gestão democrática do ensino público, na forma da lei”(BRASIL, 2016, p. 123). Dessa forma, a gestão escolar se torna um princípio constitucional, assim como a gratuidade e obrigatoriedade que já eram contempladas em textos anteriores.

Para Adrião e Camargo (2007), essa inovação está relacionada à existência, na época da elaboração da CF/1988, aos movimentos nacionais que desejavam demarcar no texto constitucional o retorno da democracia na educação pública. Outro fator importante salientado é que o termo princípio“empregado para designar, na norma jurídica 
escrita, os postulados básicos e fundamentais presentes em todo Estado de direito, ou seja, são afirmações gerais no campo da legislação a partir das quais devem decorrer as demais orientações legais" (ADRIÃO e CAMARGO, 2007, p.65).Sendo assim, a gestão democrática fica assegurada para as futuras legislações como um princípio a ser seguido, reforçado pela expressão genérica:na forma da lei, acrescida no texto constitucional. É interessante salientar também que o texto final incorporou o adjetivo público,à palavra ensino, deixando a gestão democrática exclusiva à esfera pública e não sendo mencionada em mais nenhum momento do texto da CF/1988(ADRIÃO e CAMARGO, 2007).

Oito anos após a promulgação da $\mathrm{CF} / 1988$, o artigo terceiro da LDB/1996, reforça a gestão democrática com o mesmo texto constitucional, porém o artigo quatorze apresenta-se bem mais específico:

\footnotetext{
Os sistemas de ensino definirão as normas da gestão democrática do ensino público na educação básica, de acordo com as suas peculiaridades e conforme os seguintes princípios:

I - participação dos profissionais da educação na elaboração do projeto pedagógico da escola;

II - participação das comunidades escolar e local em conselhos escolares ou equivalentes (BRASIL, 2017, p. 15).
}

Sendo assim o texto da LDB/1996 define a forma como se dará a gestão democrática da educação pública,limitando-se ao Projeto Político Pedagógico (PPP) e à participação em conselhos escolares ou órgãos equivalentes. Porém, a LDB deixa a critério dos sistemas de ensino criarem outros mecanismos de participação democrática, não garantindo que ocorram efetivamente.

Em 9 de janeiro de 2001 é sancionadaa Lei n. ${ }^{\circ}$ 10.172/2001 que institui o Plano Nacional de Educação de 2001-2010 (PNE 2001-2010), apresentado como um compromisso do presente para as gerações futuras. O PNE 20012010 determina ainda que estados e munícios, aprovem em suas casas legislativas, planos que obedeçam à hierarquia institucionalcom coerência com a gestão democrática da educação, conforme a CF/1988e a LDB/1996 (BRASIL, 2001).Isso porque o PNE 2001-2010 possui normas internas que devem ser seguidas nacionalmente e está vinculado a compromissos internacionais 
acordados pelo Brasil, e deve ter a vigência de dez anos.Em resumo, o Plano conclui que a gestão democrática nas escolas públicas deve desburocratizar a escola pública e contribuir para a descentralização nas dimensões pedagógica, administrativa e financeira, através da implementação, nos sistemas de ensino,da gestão democrática na forma de Conselhos de Educação, Conselhos Escolares e formas de escolha da direção escolare do projeto pedagógico da escola com a participação das comunidades escolar e local(BRASIL, 2001).

Em 2010 é realizada a Conferência Nacional de Educação (CONAE/2010), na tentativa de criar um espaço democrático, propiciando a ampla participação popular (BRASIL, 2014a). A CONAE/2010 serve de base para o próximo Plano Nacional de Educação (PNE), tornando-se um documento de referência para a discussão, mobilização e debate a respeito da educação, e consolidando dessa forma, o SNE (BRASIL, 2014a).É importante ressaltar que tanto o Fórum Nacional de Educação (FNE) quanto a CONAE $/ 2010^{4}$, contribuíram para a participação social na política educacional; esses espaços possibilitaram que sociedade civil e a comunidade escolar participassem de discussões a respeito da política educacional, e juntos tornamse um marco da educação nacional, possibilitando espaços de diálogos, deliberações, construções e avaliações da política educacional brasileira.

O Projeto de Lein. 8.035, de 20 de dezembrode 2010, originalmente articulado aoplanejamento educacional para o período 2011-2020, tramita nas duas casas legislativas até sua versão final aprovadasomente para o decênio 2014-2024, com a Lei n. 13.005, de25 de junho de 2014.O novo plano segue o contexto de descentralização do Sistema Nacional de Educação (SNE) e seu formato contempla as várias etapas da educação, a formação e valorização profissional, o modelo de gestão e o financiamento. O PNE 2014-2024é estruturado a partir de 20 Metas, divididas em quatro grandes blocos, somando 18, e mais duas Metas que se articulam com as demais e que são de suma importância para a gestão democrática, as Metas 19 e 20 (BRASIL, 2014b).

O primeiro bloco de Metas são as chamadas estruturantes estão as 1, 2, 3, $5,6,7,9,10$ e 11 , que visam a garantia do direito à educação básica de qualidade. No segundo grupoMetas 4 e 8 , que tem o objetivo de reduzir as desigualdades sociais e a valorizar a diversidade. O terceiro bloco asMetas 15, 16, 17 e 18buscam atingir a valorização e a formação dos profissionais da

${ }^{4}$ A CONAE/2010, possibilitou a participação de 3,5 milhões de brasileiros e brasileiras, contando com a participação de 450 mil delegados e delegadas nas etapas municipal, intermunicipal, estadual e nacional (BRASIL, 2014a). 
educação. No quartogrupo estão as Metas 12, 13 e 14, que buscam o fortalecimento do ensino superior. Já as Metas 19e 20, tratam respectivamente do modelo de gestão e do financiamento da educação. dessa forma, contribuindo para o fortalecimento da democratização da educação(BRASIL, 2014b).

Contudo, para o entendimento da questão que estamos tratando que é o modelo de gestão,nosso foco é a Meta 19, que apresenta o seguinte texto: "assegurar condições, no prazo de dois anos, para a efetivação da gestão democrática da educação, associada a critérios técnicos de mérito e desempenho e à consulta pública à comunidade escolar, no âmbito das escolas públicas, prevendo recursos e apoio técnico da União para tanto" (BRASIL, 2014c, p. 83), epara o efetivo alcance desta, são estabelecidas oito Estratégias.

As Estratégias contemplam o repasse financeiro da União para os entes federados que aprovem,em lei, formas de nomeação dos diretores(as) de escola, conselhos de acompanhamento e controle social, fóruns permanentes de educação, grêmios estudantis, associações de pais, conselhos escolares e conselhos municipais de educação, e que estes atuem como instrumentos de participação e fiscalização na gestão escolar e educacional. Estes devem colaborar para a formulação dos projetos político-pedagógicos, dos currículos escolares, dos planos de gestão escolar e dos regimentos escolares, assegurando a participação dos pais na avaliação de docentes e gestores escolares, dessa forma favorecendo os processos de autonomia pedagógica, administrativa e de gestão financeira nos estabelecimentos de ensino. (BRASIL, 2014c).

Verificarmos que a Meta 19 poderia auxiliar a efetivação da gestão democrática na educação básica pública, porém, a associar a sua efetivação a critérios técnicos de mérito e desempenhopercebe-se que ela pode estar prédeterminada, chegando a tomar sentidos diferenciados, polissêmicos e até multidimensionais. Esse fato pode estar relacionado às tecnologias que permeiam o documento. Até porque, segundo Ball (2011), estamos passando por uma profunda transformação no mundo ocidental e nas sociedades desenvolvidas no que diz respeito aos princípios de organização social, em especial no setor público. Essa transformação, causada pelo neoliberalismo, provoca mudanças no setor público, envolvendo privatizações, flexibilizações, descentralizações e regulamentações, as quais enfraquecem os governos e as estruturas democráticas locais.

Tais mudanças alteram as tecnologias de controle estatal, transformando valores e subjetividades, e essa nova economia moral do planejamento estatal 
provoca mudanças, influenciando inclusive o setor educacional. Desse modo, as políticas educativas atuais tiram sua eficiência prática de três tecnologias: mercado, gerencialismo, e performatividade (BALL, 2008). Tais tecnologias são embasadas em resultados e em prestação de contas, contribuindo para a implementação de formas de gestão características do setor privado.

Ball (2011) argumenta que tais transformações ocorridas na maioria das sociedades do mundo ocidental e das sociedades desenvolvidas têm alterado a organização e a administração da maioria dos países, em especial, no setor público, determinado pelo modelo neoliberal. Essas transformações, segundo Ball, são causadas por um processo mais amplo, de caráter político-ideológico, que substitui o discurso produtivo do planejamento fordista da produção para o pós-fordista embasado na flexibilização, no empreendedorismo e no controle.

Esse gerencialismo, assim denominado por Ball (2008), afeta as formas de pensar, sentir e agir dos sujeitos envolvidos em seus espaços de trabalho. Isso porque, para Ball (2006), é nas instituições onde ocorrem as interações e que a nova concepção de gestão é concebida e reproduzida. O autor adverte que suas considerações a respeito da reestruturação das políticas públicas e do setor educacional tornam-se claras quando se leva em conta que tais mudanças ocorrem inclusive na sociedade civil, que de certa forma acaba por ser o alvo dessas políticas.

Como solução para esse problema, Ball (2006) sugere que as políticas educacionais devam ser resolvidas nos contextos nos quais os sujeitos estão inseridos, na sua realidade, pois, na medida em que as soluções para os problemas são apresentadas por textos políticos, distantes das realidades locais, dificilmente os conflitos e os problemas serão resolvidos.Ademais, existem outros dispositivos que rondam o complexo sistema educacional e que balizam a gestão, tais como: desempenho, qualidade, padronização, parcerias, dispositivo de mudança, monitoramento, terceirizações, convênios, descentralização, regulação, disciplinarização, e regulamentação do sistema público de educação.

Para Ball, as respostas para esses problemas devem ser "criativas", já que normalmente as políticas não nos dizem o que fazer, mas sim, criam circunstâncias em um leque reduzido de opções sobre o que fazer, mesmo que seus efeitos sejam pouco eficazes. Entretanto, as respostas devem ser construídas no contexto dessas políticas, servindo de contraponto e equilíbrio para novas expectativas, e devem, ainda, estar embasadas em uma teoria crítica combinada com políticas sociais de igualdade (BALL, 2006). 
Desse modo, concordamos com Ball (2006, 2008, 2010, 2011) e Lessard (2016), ao utilizarem o termo "tecnologia de mudança", ou seja, a transformação prática entre as ideias (saberes) e práticas (ações) que transformam as relações entre o Estado e os sujeitos no âmbito escolar. Desse modo, podemos identificar claramente o gerencialismo sendo introduzido no setor público por meio do modelo de gestão democrática proposto.A democratização da escola básica pública torna-se então uma modulação da sociedade de controle, transitando entre um direito e um dever, ou talvez uma tecnologia colocada para disciplinar e reproduzir, no espaço escolar, um modelo de sociedade com políticas afirmativas.

No próximo tópico, retomamos o objetivo deste artigo, que é discutir a Meta19 e suas oito estratégias estabelecidas no PNE 2014-2014. Diante do que já apresentamos, pretende-se apontar algumas reflexões a respeito da gestão democrática proposta e como ela contribui para a gestão gerencialista.

\section{META 19: UMA TECNOLOGIA GERENCIALISTA?}

Ao analisar a Meta 19 do novo PNE, de forma bastante direta, Peroni e Flores (2014) observam que a gestão democrática proposta indica claramente um modelo gerencial, já que ela está pautada em critérios técnicos de mérito e de desempenho.Sendo assim, acreditamos que a efetivação da gestão democrática da educação básica pública, pode estar apoiada no gerencialismo descrito por Ball (2011; 2010; 2006; 2005). Isso porque o texto da Meta 19 do PNE 2014-20124 deixa bastante claro que a gestão democrática do ensino público deve estar associada a critérios técnicos de mérito e desempenho, associada à consulta pública da comunidade escolar das escolas públicas.

Para Peroni e Flores (2014), apesar de a consulta pública à comunidade escolar significar uma evolução da gestão democrática da educação no texto do PNE 2014-2024, na história da educação brasileira ela assume concepções diferentes quando é associada a critérios técnicos de mérito e desempenho. Segundo as autoras, tal critério contraria o texto aprovado na CONAE 2010, que garantia a eleição direta para gestores/as das escolas públicas.

Em nosso entendimento, esta redação tenta articular em um mesmo texto dois mecanismos de gestão que representam concepções diferentes e mesmo antagônicas de gestão, uma de matriz democrática e outra vinculada a modelos de viés gerencial, restando aos entes federados o desafio de implementar 
em conjunto critérios tão distintos. Cabe, ainda, destacar o fato de que a expressão "consulta pública" pode não significar exatamente a eleição direta de dirigentes escolares (Peroni e Flores, 2014, p.186).

Além disso, segundo relatório oficial referente ao $1^{\underline{o}}$ ciclo de monitoramento das metas do PNE 2014-2024, ao biênio 2014-2016, ao tratar da Meta 19 destaca que "não existe base de dados censitária sobre os gestores das escolas públicas brasileiras" (BRASIL, 2016, p. 432). O relatório sugere que sejam criados, no Censo Escolar, mecanismos que possibilitem caracterizar e tipificar a gestão das escolas públicas de forma mais robusta nas suas múltiplas dimensões.

Segundo a Meta 19, é estipulado inclusiveo prazo de 2 anos para a sua efetivação, prevendo recursos e apoio técnico da União para sua concretização. Ademais, outras contradições podem ser observadasnas oito Estratégias da Meta 19 que podem dificultara gestão democrática prevista no texto do PNE 20142024. Para o efetivo alcance da Meta, a Estratégia 19.1 apresenta:

19.1. priorizar o repasse de transferências voluntárias da União na área da educação para os entes federados que tenham aprovado legislação específica que regulamente a matéria na área de sua abrangência, respeitando-se a legislação nacional, e que considere, conjuntamente, para a nomeação dos diretores e diretoras de escola, critérios técnicos de mérito e desempenho, bem como a participação da comunidade escolar (BRASIL, 2014c, p. 83);

Peroni e Flores (2014, p. 186), acrescentam que a Estratégia 19.1 é de cunho gerencialista, pois está atrelada a critérios técnicos e de desempenho ao repasse de recursos financeiros "apesar de muitos artigos do Plano abordarem o regime de colaboração, os sistemas de ensino deverão obrigatoriamente adotar critérios técnicos de desempenho que vão de encontro a concepções e práticas de gestão democrática, para receber os recursos públicos a que têm já direito". Outra contradição está na nomeação dos diretores e diretoras de escola, associada à participação da comunidade escolar. Porém a Estratégia 19.1 não deixa claro como essa participação se dará.

Outro fator importante referente a essa estratégia é que "a escolha de diretores escolares no Brasil ocorre de diversas formas, envolvendo variados procedimentos, predominando hoje aqueles relacionados a algum tipo de 
indicação (política, técnica, outros), e que o processo misto de seleção e eleição se dá em apenas 12,2\% das escolas” (BRASIL, 2016, p. 433).

As demais Estratégias: 19.2, 19.4, 19.5 e 19.7, apresentam o seguinte texto:

19.2. ampliar os programas de apoio e formação aos(às) conselheiros(as) dos conselhos de acompanhamento e controle social do Fundem, dos conselhos de alimentação escolar, dos conselhos regionais e de outros e aos(às) representantes educacionais em demais conselhos de acompanhamento de políticas públicas, garantindo a esses colegiados recursos financeiros, espaço físico adequado, equipamentos e meios de transporte para visitas à rede escolar, com vistas ao bom desempenho de suas funções;19.4. estimular, em todas as redes de educação básica, a constituição e o fortalecimento de grêmios estudantis e associações de pais, assegurando-se lhes, inclusive, espaços adequados e condições de funcionamento nas escolas e fomentando a sua articulação orgânica com os conselhos escolares, por meio das respectivas representações;19.5. estimular a constituição e o fortalecimento de conselhos escolares e conselhos municipais de educação, como instrumentos de participação e fiscalização na gestão escolar e educacional, inclusive por meio de programas de formação de conselheiros, assegurando-se condições de funcionamento autônomo;19.7. favorecer processos de autonomia pedagógica, administrativa e de gestão financeira nos estabelecimentos de ensino (BRASIL, 2014c, p. 83-84).

Essas Estratégias apresentam diferentes tipos de instrumentos de participação e fiscalização na gestão escolar, denominados órgãos colegiados, formados por conselhos, associações e grêmios, bem como o favorecimento de processos que possibilitem a autonomia pedagógica, administrativa e de gestão.Os representantes destes órgãos devem participar de programas de formação, cabendo ao poder público providenciar condições plenas para o seu funcionamento, pois sua função é acompanhar, deliberar e fiscalizar a gestão do sistema de ensino em todas instâncias de governo.

Carozzi (2015), Castro (2016), Dublante(2016) e Peres (2016) estudaram os diversos fatores que levam os Conselhos Municipais de Educação (CME), como uma forma de representação colegiada, a facilitar ou dificultar a efetivação do ideário democrático. Isso se dá porque o CME, em tese, deve representar a municipalidade como um todo, pois seus membros fazem parte de todos os setores da sociedade 
civil, sendo os conselheiros eleitos pelos seus pares. Contudo, os autores apontam que o CME pode apresentar-se como um híbrido ideológico nas tomadas de decisões, ora pela vontade popular, ora pela vontade política local, dependendo das forças e dos poderes que atuam nas tomadas de decisões nessa arena de debate. Para os autores, independentemente do município estudado, é imprescindível que esse órgão colegiado deva ser um espaço de reflexão e exercício da democracia, por meio do trabalho coletivo dos seus representantes e que estes devam zelar pelo bem comum, cientes do seu papel como conselheiros.

Para Lima (2014), ao analisar a gestão democrática pela participação e pela autonomia da escola na atuação do Diretor, Coordenadores e do Conselho Escolar, verificou que estes são limitados pela rigidez do sistema educacional e pela sua forma centralizadora, deixando pouco espaço para a atuação desses atores nas tomadas de decisões. $\mathrm{O}$ autor verificou também que a relação entre família, escola e sociedade permanece distante, dificultando o processo democrático.

A Estratégia19.3, busca "incentivar os estados, o Distrito Federal e os municípios a constituírem fóruns permanentes de educação, com o intuito de coordenar as conferências municipais, estaduais e distrital, bem como efetuar o acompanhamento da execução deste PNE e dos seus planos de educação (BRASIL, 2014c, p.84)".Porém, segundo Saviani (2017), a partir do momento em que o Decreto de 26 de abril de 2017, assinado pelo presidente Michel Temer, alterou a Lei $n$. 13.005/2014, que trata da execução e do monitoramento do PNE 20142024, o Fórum Nacional de Educação (FNE) foi deixado em função secundária na realização da III CONAE, atribuindo a supervisão e a orientação das atividadesda conferencia para a Secretaria Executiva do MEC. Esse fato deixou a Estratégia 19.3bastante fragilizadaquanto à participação democrática.

A Estratégia 19.6, busca "estimular a participação e a consulta de profissionais da educação dealunos(as) e de seus familiares na formulação dos projetos político-pedagógicos, currículos escolares, planos de gestão escolar e regimentos escolares, assegurando a 
participação dos pais na avaliação de docentes e gestores escolares (BRASIL, 2014c, p. 83-84)"'.Segundo o relatório do primeiro ciclo de monitoramento que avaliou a participação de profissionais da educação, pais e alunos na formulação dos projetospolítico-pedagógicose na constituição do conselho escolar,constatou-se quehouve a participação da equipe escolar, porém não foi percebida a de pais e alunos na atividade. Quanto ao projeto pedagógico, constatou-se que $89,1 \%$ das escolas, afirmaram que contaram com algum tipo de discussão somente com a equipe escolar, sem a presença de alunos e familiares (BRASIL, 2016).

Paz (2015) acrescenta que no âmbito municipal, as estratégias que garantem a participação de toda comunidade escolar não é garantia para atingir a gestão democrática do ensino público. Isso porque o processo de institucionalização da gestão dos sistemas de ensino segue definido por marcos legais, historicamente demarcados, e que na prática acabam por prejudicar o processo democrático. $\mathrm{O}$ autor levanta cinco aspectos apontados pela sua pesquisa que inviabilizam a participação e a avaliação do processo democrático: (i) a falta de conhecimento, por parte dos membros gestores e da comunidade escolar e local, de todo o processo de construção coletiva, divulgação e conhecimento dos textos legais; (ii) o fato de o órgão municipal responsável pelo SME estar à mercê de grupos políticos locais, que levam ao clientelismo e ao patrimonialismo; (iii) a falta de autonomia e de conhecimento por parte dos integrantes do Conselho Municipal de Educação, responsáveis pelas funções: normativa, consultiva, mobilizadora e fiscalizadora; (iv) a pouca autonomia, no ambiente escolar, nos processos de eleição de gestor e na elaboração do Projeto Político Pedagógico (PPP), faltando não só conhecimento mas também divulgação desses dispositivos que regulamentam tais instrumentos de gestão; e (v) a falta de definição, de execução e de avaliação das políticas educacionais de ensino apresentadas nos documentos oficiais do município, a exemplo dos Planos Municipais de Educação (PME).

Por último, temos a Estratégia 19.8, que pretende "desenvolver programas de formação de diretores e gestores escolares, bem como aplicar prova nacional específica, a fim de subsidiar a definição de critérios objetivos para o provimento dos cargos, cujos resultados possam ser utilizados por adesão" 
(BRASIL, 2014c, p.84). Esta Meta não especifica de forma clara como será a formação,muito menos como ocorrerá a prova nacional que provavelmente avaliaria o cargo de gestor.

Aquino (2015), ao discutir a construção de significados sobre a gestão escolar democrática contida no Plano Nacional de Educação PNE 2014-2024, concluiu que a Lei que homologou o plano foi aprovada em ano eleitoral, deixando dúvidas sobre as suas intencionalidades. Mesmo que o PNE 2014-2024 tenha superado as expectativas de céticos, ele representa múltiplos fluxos e disputas no cenário político nacional, deixando de atender às expectativas de todos os envolvidos no processo, ao considerar o número de emendas que a lei sofreu nas duas casas legislativas. A autora salienta:

\begin{abstract}
Assim uma das perdas para todos os envolvidos na luta em defesa da gestão democrática foi quando ficou estabelecido, na Meta 19 do Plano Nacional de Educação que está contido na Lei 13.005/2014, que a gestão democrática seria apenas para o ensino público. A ideia é que todos precisamos construir uma sociedade democrática, então por que apenas os alunos da escola pública deveriam "aprender" a ser democráticos? Entende-se que é na prática que se aprende a conviver numa sociedade democrática, já que esta aprendizagem ocorre no dia a dia da participação em processos de correlação de forças. (AQUINO, 2015, p. 134).
\end{abstract}

De modo geral, as políticas que definem a gestão democrática indicam que estas são implantadas somente para cumprir aspectos legais, dificultando na realidade das escolas públicas a sonhada democratização da educação. Quanto ao Conselho Escolar, que tem por definição as funções consultiva, deliberativa, normativa e fiscalizadora, conforme regimento oficial, observa-se que este acaba por cumprir somente a função de fiscalizar os recursos advindos de programas governamentais, deixando de colaborar com a gestão escolar como um todo.

Contudo, a implantação de um ideal democrático de gestão das escolas públicas, inserido em uma nova ordem mundial neoliberal e sua ideologia, pode direcionar as políticas públicas educacionais em um movimento dialético, pois, a princípio, essas políticas podem tomar sentidos diferenciados, podendo levar a textos políticos estrategicamente polissêmicos e implicar práticas multidimensionais de gestão. 


\section{CONSIDERAÇÕES FINAIS}

Pretendemos, neste artigo,abordar a Meta 19 do PNE 2014-2024, ao questionarmos se estamos diante de uma conquista da gestão democrática da educação pública assegurada na CF/1988, ou se estamos diante do fortalecimento de uma gestão gerencialista descrita por Ball (2006, 2005). Isto porque da maneira que os enunciados do discurso da gestão democrática proposta na Meta 19 do PNE 2014-2024pode se configurar-se como uma nova forma de poder derivada da cultura empresarial, que busca a competitividade no setor público, já que o plano estabelece políticas educacionais que influenciaram o SNE para os próximos dez anos.

Quando o Estado utiliza de um discurso democrático somente para controlar e fiscalizar a educação básica pública,focado somente em um modelo gerencialista de gestão, deixa de lado os fundamentos democráticos como soberania, cidadania, dignidade da pessoa humana, valores sociais, livre iniciativa, e pluralismo político. Sendo assim, o discurso da Meta 19 pode contribuir para tornar o Estado cada vez mais fortalecido, incentivando principalmente políticas neoliberais. Isso porque as políticas, segundo Lessard (2016), transmitem afirmações, produzem realidades e significados, alterando práticas sociais e muitas vezes privilegiando visões e interesses específicos.

Ao contextualizarmos a gestão democrática da educação pública desde a CF/1988, percebe-se que as políticas para a educação sofrem influência da política neoliberal, mesmo com a resistência de alguns setores da sociedade organizada e dos movimentos sociais (BOLLMANN, 2010; ADRIÃO e CAMARGO, 2007). Mesmo assim, a gestão democrática do ensino público se torna um princípio constitucional, seguido nos principais documentos regulatórios da educação brasileira - LDB/1996, PNE 2001-2011 e PNE 20142024.

O novo PNE 2014-2024, elaborado após ampla participação popular na CONAE/2010, possui uma meta que trata exclusivamente da gestão democrática da educação pública, a Meta 19, possuindo 8 Estratégias para a sua efetivação. As estratégias, além de preverem o auxílio do poder público para a efetivação da gestão democráticaela ocorrerá através de: formas de escolha de diretores(as) de escola, órgãos colegiados de acompanhamento e controle socialcomo conselho escolar e conselhos de educação, fóruns permanentes de educação, projetos político-pedagógicos, planos de gestão escolar e regimentos 
escolares. Dessa forma, assegurando a participação da comunidade escolar na avaliação e fiscalização da escola, a fim de alcançar a autonomia pedagógica, administrativa e de gestão financeira do ensino público (BRASIL, 2014c).

Porém, a Meta 19 da forma que foi estabelecida no documento, pode levar a sentidos polissêmicos e até multidimensionais, pois os princípios de organização do setor público causado pelas políticas neoliberais, provocando mudanças no direcionamento das políticas públicas, através de privatizações, flexibilizações, descentralizações e regulamentações inclusive na área educacional (BALL, 2011). Esse fato pode ser percebido, segundo Ball (2008), pois as políticas públicas cada vez mais estão próximas do setor privado alterandoo modelo de organização e de administração na maioria dos países desenvolvidos.

Ball (2008), denomina esse fato de gerencialismo, afetando inclusive as relações no ambiente de trabalho e aumentando a competitividade e a busca pela performatividade. Sendo assim, a democratização da escola pública da maneira que é apresentada, deixa de ser um direito e passa a ser um dever, uma maquinaria para manutenção de uma sociedade de controle (CERVI, 2013). Tal fato pode ser percebido na Meta 19 do PNE 2014-2024, pois a associação da gestão democrática acritérios técnicos de mérito e desempenho e com a fiscalização pública,realizada pela comunidade escolar e local, apresenta concepções não só diferentes mas também antagônicas quanto aos princípios democráticos (PERONI e FLORES, 2014).

Concordamos com Dewey (2008) ao afirmar que a democracia não pode ser vista apenas como um modelo utópico de uma sociedade ideal do futuro, mas ela antes disso, deve ser um meio de se constituir o presente, com princípios de liberdade e individualidade para todos. O autor vê a democracia não como uma forma de governo, mas como um modo de vida, um modo de ser e viver em comunidade e não um sistema de governo. Dewey (2008) acredita que essa ideia necessita de um lugar para acontecer, que para este trabalho apontamos como sendo espaço escolar, onde a ideia de democraciapossa nascer e se preservar. 


\section{REFERÊNCIAS}

ADRIÃO, T.; CAMARGO, R. B. A gestão democrática na Constituição Federal de 1988. In: OLIVEIRA, R. P.; ADRIÃO, T. (Orgs.). Gestão, financiamento e direito à educação: análise da LDB e da Constituição Federal. São Paulo: Xamã, 2001. p. 63-72. Disponível em: https://www.researchgate.net/publication/312387735_Contribuicoes_ao_debate _sobre_gestao_democratica_da_educacao_foco_em_legislacoes_municipais_sul -rio-grandenses. Acesso em: 20 de maio de 2019.

AQUINO, L. M. S. Formulação do plano nacional de educação 2014-2024: a gestão democrática da escola na política pública. 2015. 251 f. Tese (Doutorado em Educação) - Universidade Federal do Rio Grande do Sul, Porto Alegre, 2015 .

BALL, S. Profissionalismo, gerencialismo e performatividade. Cadernos de Pesquisa [online], v. 35, n.126, p.539-564, 2005.

. Sociologia Das Políticas Educacionais E Pesquisa Crítico-Social: Uma Revisão Pessoal Das Políticas Educacionais E Da Pesquisa Em Política Educacional. Currículo sem Fronteiras, v.6, n.2, pp.10-32, Jul./Dez 2006.

. The Educations debate: policy and politicsin the twenty-first Century. Bristol: Policy Press, 2008.

Performatividades e fabricações na economia educacional: rumo a uma sociedade performativa. Educação \& Realidade [online], Porto Alegre, v. 35, n. 2, p. 37-55, maio/ago. 2010.

; MAINARDES, J. (Org.). Políticas educacionais: questões e dilemas. São Paulo: Cortez, 2011.

BOLLMANN, M. G. N. Revendo o Plano Nacional de Educação: proposta da sociedade brasileira. Educação \& Sociedade, Campinas, v. 31, n. 112, p. 657 676,2010 .

BRASIL. Plano nacional de educação - Brasília: Senado Federal, UNESCO, 2001. 186p.

. CONAE 2014a, Documento Referência. Disponível em:

http://conae2014.mec.gov.br/. Acesso em: 23 de out. de 2016. 
Planejando a Próxima Década: Conhecendo as 20 Metas do Plano Nacional de Educação. Presidência da República, Ministério da Educação, Secretaria de Articulação com os Sistemas de Ensino, 2014b, p. 62. Disponível em: http://pne.mec.gov.br/images/pdf/pne_conhecendo_20_Metas.pdf. Acessado em: 23 de out. de 2016.

. Plano Nacional de Educação (PNE). Plano Nacional de Educação 2014-2024 [recurso eletrônico]: Lei no 13.005, de 25 de junho de 2014, que aprova o Plano Nacional de Educação (PNE) e dá outras providências Brasília: Câmara dos Deputados, Edições Câmara, 2014c, 86 p. - (Série legislação; n. 125).

Constituição da República Federativa do Brasil: texto constitucional promulgado em 5 de outubro de 1988, com as alterações determinadas pelas Emendas Constitucionais de Revisão nos 1 a 6/94, pelas Emendas Constitucionais nos 1/92 a 91/2016 e pelo Decreto Legislativo no 186/2008. Brasília: Senado Federal, Coordenação de Edições Técnicas, 2016. 496 p. ISBN: 978-85-7018-698-0.

- Instituto Nacional de Estudos e Pesquisas Educacionais Anísio Teixeira. Relatório do $1^{\circ}$ ciclo de monitoramento das metas do PNE: biênio 2014-2016. - Brasília, DF, Inep, p.590, 2016.ISBN 978-85-7863-052-21. Educação - Brasil. 2. Plano Nacional de Educação. I. Título.CDU 37(81)

LDB: Lei de diretrizes e bases da educação nacional. Brasília: Senado Federal, Coordenação de Edições Técnicas, 2017. Conteúdo: Leis de diretrizes e bases da educação nacional - Lei no 9.394/1996 -Lei no 4.024/1961.

CAROZZI, E. S. Organização e gestão escolar: uma análise do Conselho Escolar na rede pública municipal de Cascavel. 2015. 190 f. Dissertação (Mestrado em Educação) - Universidade Estadual do Oeste do Paraná, Cascavel, 2015.

CASTRO, S. B. D. Conselho Municipal de Educação de Feira de Santana: o contexto da produção dos textos oficiais. 2016. 126 f. Tese (Doutorado em Educação) - Universidade Federal da Bahia, Salvador, 2016.

CERVI, G. M. Política de gestão escolar na sociedade de controle.Rio de Janeiro: Achiamé, 2013. 
DEWEY, John. Democracia Cooperativa: escritos políticos escolhidos por John Dewey: 1927-1939. Organizado por Augusto de Franco e Thamy Pogrebinschi. Porto Alegre: EDIPUCRS, 2008.

DUBLANTE, C. A. S. Gestão democrática: o processo de representação dos conselhos escolares na rede pública municipal de São Luís, MA. 2016. 338 f. Tese (Doutorado em Educação) - Universidade Federal do Rio Grande do Norte, Natal, 2016.

FOUCAULT, M. Microfísica do poder: organização, introdução e revisão técnica de Roberto machado. 4. ed. Rio de Janeiro, RJ: Paz e Terra, 2016.

LESSARD, C. Políticas educativas: a aplicação na prática. Petrópolis, RJ: Vozes, 2016.

LIMA, F. A. de. Gestão escolar democrática, participação e autonomia: realidade ou utopia?. 2014. 144 f. Dissertação (Mestrado em Gestão Pública) Universidade Federal do Rio Grande do Norte, Natal, 2014.

MACHADO, R. Por uma Genealogia do Poder. In: FOUCAULT, Michel. Microfísica do Poder. Rio de Janeiro: Paz e Terra, 2016.

PAZ, V. O. Institucionalização da gestão democrática da educação como política pública no Sistema Municipal de Ensino de Igarapé-Açu, Pará. 2015. 228 f. Tese (Doutorado em Educação) - Universidade Federal do Pará, Instituto de Ciências da Educação, Belém, 2015.

PERES, A. P. F. Gestão democrática e conselhos de escola no município de Araraquara S/P. 2016. 134 f. Tese (Doutorado em Educação Escolar) Universidade Estadual Paulista "Júlio de Mesquita Filho", Faculdade de Ciências e Letras, Araraquara, 2016.

PERONI. V. M. V.; FLORES, M. L. R. Sistema nacional, plano nacional e gestão democrática da educação no Brasil: articulações e tensões. Educação, Porto Alegre, v. 37, n. 2, p. 180-189, maio/ago. 2014.

SAVIANI, D. Sistema Nacional de Educação e Plano Nacional de Educação: significado, controvérsias e perspectivas - 2 . Ed ver. e ampl. - Campinas, SP: Autores associados, 2017.

Recebido em 23/05/2019

Aprovado em 07/10/2019 